\title{
Entre o perigo da indiferença e o risco de ser afetado: a gestão das emoções em investigações policiais de pornografia infantil ${ }^{1}$
}

Laura Lowenkron*

\section{Resumo}

0 objetivo do artigo é analisar os efeitos micropolíticos das emoções para pensar o trabalho moral exercido por e sobre o olhar investigativo policial diante de imagens de pornografia infantil. Em termos empíricos, o texto é baseado em uma pesquisa de campo etnográfica realizada entre março de 2009 e dezembro de 2010 no Núcleo de Prevenção e Repressão a crimes via internet, o NUNET, da Polícia Federal no Rio de Janeiro. Por fim, é discutida a importância epistemológica de ter sido "afetada", durante o trabalho de campo, pela visualização de cenas diante das quais as reações emocionais supostamente mais "espontâneas" e moralmente esperadas são o horror profundo e a repulsa imediata. Argumenta-se que essa (des)afetação foi o que possibilitou à pesquisadora incorporar e, assim, compreender o esfriamento emotivo que define a perspectiva investigativa policial.

\section{Palavras-chave}

Pornografia infantil. Emoções. Etnografia

\section{Abstract}

The aim of this article is to analyze the micropolitical effects of emotions regarding the moral job exercised by and over the police investigative view when dealing with images of

\footnotetext{
* Laura Lowenkron é professora adjunta do Departamento de Políticas e Instituições de Saúde do Instituto de Medicina Social (IMS) da UERJ. Doutorou-se em Antropologia Social pelo Museu Nacional da UFRJ (2012) e é mestre pela mesma instituição (2008). É autora do livro O Monstro contemporâneo: a construção social da pedofilia em múltiplos planos (Eduerj, 2015) e de diversos artigos em revistas cientificas e em coletâneas nacionais e internacionais. Ao longo dos últimos anos, tem atuado principalmente nos seguintes temas: violência sexual, infância/ menoridade, pedofilia e tráfico de pessoas. Email:lauralowenkron@gmail.com.(UFRRJ).

${ }^{1}$ Este artigo é baseado no capítulo 7 da minha tese de doutorado (LOWENKRON, 2012). Uma primeira versão deste texto foi apresentada no GT 28 - Emoções, Política e Trabalho da $28^{a}$ Reunião Brasileira de Antropologia (RBA), em julho de 2012. Agradeço a Maria Claudia Coelho e a Susana Durão pelos comentários e sugestões nessa ocasião.
} 
child pornography. In empirical terms, this text tis based on an ethnographic field research conducted between March 2009 and December 2009 in the Prevention and Repression Center on cybercrimes of Rio de Janeiro's Federal Police. Lastly, it discusses the epistemological importance of being "affected", during the field work, by scenes which supposedly produce more "spontaneous" and morally expected emotional reactions of profound horror and immediate disgust. It is argued that this (un)affectedness is what made it possible for the researcher to incorporate and thus comprehend the emotional coldness that defines the investigative police perspective.

\section{Keywords}

Child pornography. Emotions. Ethnography.

\section{Introdução}

Partindo do pressuposto de que as respostas emocionais são tecidas não apenas histórica e culturalmente, mas também são produtos e produtoras de relações de poder (LUTZ, ABU-LUGHOD, 1990; COELHO, 2010), o objetivo deste artigo é analisar os efeitos micropolíticos das emoções para pensar o trabalho moral exercido por e sobre o olhar investigativo policial diante de imagens de pornografia infantil. Confiro particular atenção à centralidade da gestão das expressões emotivas em relação a essas cenas na fabricação das subjetividades de investigadores e investigados, bem como na delimitação de fronteiras e hierarquias sociais (MILLER, 1997). Em termos empíricos, o texto é baseado em uma pesquisa de campo etnográfica realizada entre março de 2009 e dezembro de 2010 no Núcleo de Prevenção e Repressão a crimes via internet, o NUNET, situado na Delegacia de Defesa Institucional da Superintendência Regional da Polícia Federal no Rio de Janeiro.

Meu principal argumento é o de que o dispositivo emotivo é não apenas eficaz no processo de acusação criminal dos investigados (os "pedófilos" que consomem e divulgam as imagens), mas também uma modalidade de governo que constitui e/ou ameaça a própria subjetividade do agente policial que exerce tal atividade de investigação criminal. De um lado, a gestão das emoções opera como estratégia de regulação e produção dos sujeitos investigados como "criminosos", "pedófilos" e "monstros". Esta 
tecnologia de governo ${ }^{2}$ é baseada no saber-poder prático dos policiais que selecionam estrategicamente as cenas pornográficas capazes de produzir o sentimento de "repugnância" e, portanto, o efeito de desumanização dos acusados perante os olhos dos agentes estatais responsáveis por julgar a materialidade e a autoria do crime. De outro, o olhar policial também está exposto ao escrutínio e ao risco de ser perigosamente afetado e contaminado pelas cenas pornográficas produzidas por e para o olhar perverso e transgressivo do "pedófilo".

Discuto, por fim, a importância epistemológica de ter sido "afetada", nos termos de Favret-Saada (1990), pela visualização de imagens de pornografia infantil e pelo esfriamento emotivo que define a perspectiva investigativa policial. A autora utiliza essa expressão no contexto de seu estudo sobre a feitiçaria na região do Bocage francês para se referir ao livre jogo de afetos, inicialmente desprovido de representação, que se atualiza em situações de comunicação involuntária e não intencional entre o etnógrafo e seus interlocutores durante o trabalho de campo. Alertando que isso não se confunde com empatia ou identificação pessoal, ela considera que esses momentos nos quais o pesquisador é "afetado" são dotados de especial valor heurístico, sendo esse justamente o diferencial da pesquisa etnográfica. Ao destacar a importância de fazer da participação um instrumento de conhecimento, a autora mostra que a dimensão afetiva do trabalho de campo é o que permite ao pesquisador capturar não simplesmente "representações nativas" (como o método de perguntas e respostas), mas também aspectos não verbais e involuntários da experiência humana.

Essa dimensão incorporada da produção de conhecimento antropológico foi também fundamental para a minha compreensão sobre esse trabalho policial, que implicava a visualização e a gestão cotidiana de fotografias e vídeos de pornografia infantil. No início da pesquisa, olhar as cenas causava-me desconforto enorme e um mal-estar indescritível. Entretanto, procurei não demonstrar aos meus interlocutores o meu estado de choque, manifestando apenas um desconforto discreto para que não parecesse aos policiais que aquilo seria insuportável para mim, o que prejudicaria

\footnotetext{
${ }^{2}$ A expressão "tecnologia de governo" e a ênfase na mecânica não apenas negativa e repressiva, mas também positiva e produtiva do poder, isto é, na sua dimensão formadora e produtora de subjetividades são evidentemente baseadas nas formulações teóricas de Foucault (ver, por exemplo, 1988, 1997, 2009).
} 
o andamento da etnografia. À medida que passei a ser cotidianamente "afetada" pelas mesmas forças que afetam os policiais que realizam essa tarefa investigativa e fui agitada pelas sensações, percepções e pensamentos daqueles que estão envolvidos nessa atividade, pude ter uma nova perspectiva sobre essas imagens e, consequentemente, sobre o trabalho moral exercido sobre elas por meus interlocutores de pesquisa. Ao longo deste artigo, procuro reconstruir o percurso que me permitiu incorporar e entender o intrigante deslocamento e esfriamento emotivo em relação a cenas diante das quais as reações emocionais supostamente mais "espontâneas" e moralmente esperadas são o horror mais profundo e a repulsa imediata.

\section{Entrando em campo e conhecendo as cenas}

Logo no meu primeiro dia de pesquisa de campo no NUNET, vivi uma espécie de "ritual de iniciação". Uma policial que auxiliava os dois agentes do núcleo em algumas investigações abriu uma pasta em seu computador na qual ficava armazenado o acervo de imagens enviadas por um de seus "alvos". Apareceram instantaneamente na tela cerca de sessenta miniaturas de arquivos de fotos e vídeos de pornografia infantil. Ela foi clicando nas imagens para aumentá-las. Cito um trecho do meu diário de campo no qual procurei registrar a diversidade de práticas sexuais encenadas, bem como algumas das minhas primeiras impressões sobre as cenas:

\footnotetext{
"Sexo oral e vaginal, meninas fazendo performances eróticas, meninas sendo molestadas por adultos, várias crianças juntas interagindo sexualmente, homens adultos ejaculando no rosto ou na genitália de meninas. Há uma performance bastante chocante, que chamei de 'Pequena Miss Sunshine'3 e que a policial me
}

\footnotetext{
${ }^{3}$ Esse é o titulo de um filme norte-americano, lançado em 2006, que conta a história de uma família que sai do Novo México para a Califórnia para levar a desengonçada filha mais nova, Olive, para participar do concurso de beleza infantil "A Pequena Miss Sunshine". Enquanto as demais crianças apresentavam figurinos sofisticadíssimos e performances de dança tecnicamente ensaiadas, a inusitada coreografia encenada por Olive ensinada pelo avô - que fora expulso de uma casa de repouso pelo uso de drogas - é repleta de elementos e movimentos eróticos que são reproduzidos de maneira ingênua e cômica pela menina e chocam a plateia, por não corresponderem ao ideal estético infantil esperado e encenado ao longo do evento.
} 
apresentou dizendo que 'seria cômico se não fosse trágico', na qual a menor não é apresentada em uma condição de passividade. Trata-se do vídeo de uma menina aparentando ter entre 6 e 8 anos, fantasiada e usando um óculos escuros enorme, faz uma performance de striptease. Ela tira a roupa, masturba-se, dança, faz poses eróticas com muita desenvoltura. A idade das crianças que aparecem nas imagens varia desde bebê até menina púberes, mas a maioria é impúbere e aparenta ter entre 6 e 9 anos. A pior cena é um vídeo que mostra o estupro de um bebê de menos de 1 ano. A criança chora e o homem coloca uma toalha na sua cara para abafar o som. O homem adulto penetra e agride o bebê. A policial conta que foi quando o delegado viu esse vídeo que ele resolveu prender o pedófilo que envia essas imagens e instaurou o inquérito".

Mobilizada frente às imagens (especialmente a do estupro do bebê), perguntei à policial se ela não se sentia mal de ficar olhando essas cenas. Ela respondeu que, se ficassem pensando na perspectiva das crianças, não conseguiriam realizar o trabalho. "O meu foco é reunir a maior quantidade de provas para ajudar a prender o pedófilo", explicou. Com o tempo, pude compreender o sentido daquele "ritual de iniciação", que exerceu tanto sobre o meu intelecto quanto sobre o meu corpo uma espécie de pedagogia política dos sentimentos (LOWENKRON, 2012). A exposição às fotografias e aos vídeos pornográficos, associada à narrativa sobre a reação do delegado, serviam para começar a me ensinar simultaneamente quais eram as respostas emotivas e morais apropriadas diante das cenas de pornografia infantil naquele contexto e como era possível manipular estrategicamente o potencial emotivo e persuasivo de certas imagens, cuidadosamente selecionadas, para garantir a eficácia da acusação criminal.

Como se pode verificar pela reação do delegado descrita por minha interlocutora, a conduta do consumidor e difusor de pornografia infantil é julgada e condenada menos por aquilo que ele faz (ver e divulgar imagens) do que por aquilo que esse crime revela sobre seus desejos e fantasias sexuais, isto é, sobre a subjetividade do criminoso. O que quero dizer é que, se de um lado, as fantasias sexuais são entendidas pelos policiais como expressão de periculosidade, de outro, elas mesmas configuram um objeto de condenação moral que influencia o processo de acusação criminal, uma vez que são interpretadas como indícios da existência de um monstro moral capaz de se excitar sexualmente até mesmo com imagens tão degradantes e violentas como a do estupro de um bebê. 
Quanto mais nova a criança retratada na foto ou no vídeo e mais grave a violência encenada, maior será a capacidade da imagem pornográfica de produzir os sentimentos de "repugnância", "horror" e "indignação". Os efeitos micropolíticos dessas emoções garantem não só uma resposta penal imediata, mas também a fabricação moral do acusado como "pedófilo" e "monstro". Dessa maneira, instaura-se um poderoso e sutil mecanismo institucional de diferenciação social entre o olhar "perverso", de um lado, e o olhar "protetivo" do denunciante indignado ou o olhar "investigativo" e "especializado" do policial, de outro. Essa delimitação de fronteira através do processo de criminalização das imagens impede que outros espectadores que eventualmente as visualizem sejam confundidos com o "monstro".

A hipótese que pretendo desenvolver é a de que a gestão policial e o enquadramento criminal da pornografia infantil buscam neutralizar os efeitos perigosamente poluidores da ampla circulação no espaço público da internet dessas representações pornográficas dos corpos infantis que, como afirma Rabelo (2012), não deveriam ter vindo a público. Para isso, é preciso controlar as chaves interpretativas que delimitam respostas emotivas perante aquilo que jamais poderia ter sido incluído no nosso campo visual e imaginativo.

Se o modo pelo qual a fotografia é enquadrada estrutura a moldura interpretativa que delimita a percepção, como adverte Butler (2009), o maior perigo da pornografia infantil talvez seja o fato de que, como toda imagem pornográfica, ela é produzida com o intuito de produzir um efeito de excitação sexual no espectador. Conforme aponta Díaz-Benitez (2010), "há, no pornô, uma intenção deliberada de gerar efeito" (Ibid, p.87). A expectativa, segundo a autora, é instigar o espectador a fazer sexo, a masturbar-se ou, ao menos, imaginá-lo. Leite Jr. (2006), por sua vez, afirma que : "a pornografia é comumente considerada como aquilo que transforma o sexo em produto de consumo, está ligada ao mundo da prostituição e visa à excitação dos apetites mais 'desregrados' e 'imorais'”. (Ibid, p.32). No caso da pornografia infantil, esses efeitos são particularmente perigosos e monstruosos, mesmo quando circunscritos ao plano das fantasias. Vejamos como as respostas emotivas e os riscos da degeneração moral pelas imagens são gerenciados pelos policiais responsáveis por analisá-las no contexto das investigações criminais. 


\section{Entre o perigo da indiferença e o risco de ser afetado}

Um delegado recém-chegado na área comentou que estava um pouco receoso com a nova atividade, porque tinha uma filha de 8 anos e não sabia que efeito poderia ter de ficar observando aquele tipo de imagem. Ao mesmo tempo, afirmava que não podia e nem iria deixar de examinálas porque era parte do seu ofício. "Eu não posso emitir uma opinião, dar um despacho, tomar uma decisão em cima de alguma coisa que eu não analisei a materialidade. É como indiciar alguém por homicídio sem ver o 'presunto' [cadáver]", resumiu ele. A exposição visual contínua de imagens de pornografia infantil vai produzindo uma frieza comparada àquela necessária para lidar com os ferimentos corporais no exercício clínico da medicina: "é igual médico, médico olha e vê: esse braço dá pra salvar? Vai dar muito trabalho, é melhor cortar logo". "Vai gerando uma certa frieza no cotidiano?", pergunto. “Vai, exatamente. Eu já olho para aquelas fotos como se nem fosse gente, como se fosse desenho animado...", explica o agente.

A desumanização das crianças e a consequente insensibilidade diante das cenas poderiam levar ao borramento das fronteiras que separam o "monstro" dos "benfeitores" (denunciantes, policiais, juízes e outros espectadores "chocados", "horrorizados" e "indignados"). Entretanto, no contexto da investigação criminal, o esfriamento emotivo pode ser moralmente legitimado pela necessidade de "distanciamento clínico" (clinical detachment), nos termos de Richardson (2000), exigido para examinar ${ }^{4}$ as imagens de pornografia infantil. Ao utilizar essa expressão para se referir à postura necessária para a realização do estudo de anatomia, o autor destaca que essa atitude carrega tanto uma conotação positiva de objetividade quanto negativa de falta de sensibilidade ${ }^{5}$. Essa dupla conotação é apontada também por Lutz (1988), ao examinar as diferentes concepções euro-

\footnotetext{
${ }^{4}$ Como sugere Susan Sontag (2003), “o termo 'examinar', mais clínico, substitui 'olhar'”. (Ibid, p.78).

${ }^{5}$ Nos termos do autor: "o estudo da anatomia através da dissecação requer dos seus práticos a efetiva supressão e suspensão de muitas das respostas físicas e emocionais normais para a mutilação intencional do corpo de outro ser humano [...] O termo 'clinical detachment' (distanciamento clínico) carrega tanto a conotação positiva de objetividade quanto a negativa de falta de sensibilidade" (RICHARDSON, 2000, p. 30-31 apud FERREIRA, 2009, p.31, tradução minha).
} 
americanas sobre as emoções. Como sintetiza Coelho (2010), retomando os argumentos desta autora, "em relação ao pensamento, a emoção situase no polo negativo, sendo o pensamento a forma valorizada; quando em oposição ao distanciamento, a emoção é o polo positivo, o distanciamento sendo algo a ser evitado" (Ibid, p.267).

$\mathrm{O}$ esfriamento emotivo e suas ambiguidades morais podem ser ainda mais bem percebidos por meio do relato de outro agente do NUNET sobre os diferentes estágios emocionais que definem a carreira dos policiais que se dedicam à análise de imagens de pornografia infantil. $\mathrm{O}$ agente explica que no início há um misto de curiosidade e choque. Depois vem a tristeza e a revolta que, segundo ele, decorrem em grande parte da frustração por perceber que, apesar do seu trabalho, não se resolve o problema, parece que a quantidade de "casos" está sempre aumentando. Com o tempo o profissional acaba se acostumando e não se choca mais tanto, apesar de considerar que isso não é bom. Nas palavras do agente:

\footnotetext{
“No início, dá uma curiosidade. Você fica querendo ver e depois diz: nossa, olha o que eles fazem... Isso existe... Depois, aquilo vira normal. Normal, não, mas faz parte da rotina, do trabalho. No terceiro estágio, você rotinizou tanto que começa a perder a sensibilidade, achar aquilo normal. Isso não é bom. Quando percebi isso, parei de olhar, passei a evitar olhar.
}

A fim de compreender os riscos associados a esse esfriamento emotivo, é preciso lembrar que imagens de violência, sofrimento e atrocidades podem suscitar reações opostas. Nos termos de Miller, "é lugar comum que o repugnante possa atrair tanto quanto repelir" (1997, p.x, tradução minha). Essa afirmativa é particularmente pertinente em relação à pornografia infantil, tanto que parte significativa do horror atribuído a essas imagens é o fato de elas despertarem prazer e excitação sexual em muitas pessoas. "Tem tanta gente interessada nisso por aí, tanto que tem todos esses inquéritos", afirmou um delegado, ao justificar a nova recomendação do Ministério Público Federal de não mais expor as fotografias nos autos dos inquéritos para evitar que as imagens fossem visualizadas por algum "curioso".

Durante o período de pesquisa de campo no NUNET, li o livro Diante da Dor dos Outros, de Susan Sontag (2003), que discute os impactos emotivos das imagens de guerra. A autora coloca em questão a proposição da escritora Virginia Woolf segundo a qual "não sofrer com essas fotos, não sentir repugnância diante delas, não lutar para abolir o que causa 
esse morticínio, essa carnificina - para Woolf, essas seriam reações de um monstro moral" (SONTAG, 2003, p.13). Sontag desconstrói esse pressuposto moral argumentando que há muitos usos para as inúmeras oportunidades oferecidas pela vida moderna de ver - à distância, por meio da fotografia - a dor de outras pessoas, bem como diferentes respostas emocionais possíveis.

"O choque pode tornar-se familiar. O choque pode enfraquecer [...]. As pessoas têm meios de se defender do que é perturbador. [...] Assim como a pessoa pode habituar-se ao horror na vida real, pode habituar-se ao horror de certas imagens" (Idem, p.70).

Daí emerge o segundo dilema moral a ser desconstruído pela autora: "o argumento de que a vida moderna consiste em uma dieta de horrores que nos corrompe e a que nos habituamos gradualmente" (Idem, p.89). Segundo ela, essa é uma ideia básica da crítica da modernidade que seria tão antiga quanto a própria modernidade. Ela desnaturaliza também essa crítica afirmando que a força moral da imagem depende da maneira como é usada, dos lugares onde é vista e da frequência com que é vista (Idem, 88). Assim, aquilo que poderia parecer insensibilidade do espectador passa a ser entendido como um efeito do contexto e do suporte de visualização.

Inspirada por essa formulação de que os diferentes usos e contextos de visualização de um mesmo tipo de imagem levam a reações emocionais diferenciadas no observador, aos poucos percebi que o esfriamento dos agentes diante de fotos e vídeos de pornografia infantil não deveria ser entendido como o efeito de uma dessensibilização ou um distanciamento moral, que tanto lhes assombrava. Essa postura emocional poderia, ao invés disso, ser interpretada como o resultado de um ofício o qual exige um "olhar clínico" (em oposição ao "olho leigo" dos denunciantes indignados) ${ }^{6}$ e dos suportes de visualização que favorecem a constituição de uma nova perspectiva em relação às cenas direcionadas à busca por "indícios". Desse modo, não é mais a dimensão erótica e violenta das fotografias que fica em

\footnotetext{
"A oposição "olho-clínico" / "olho leigo" aqui formulada é baseada nas formulações de Ginzburg (1989). Ao traçar uma analogia entre os métodos de Morelli, Sherlock Holmes e Freud, o autor sugere que o "paradigma indiciário" que define os três é baseado na semiótica médica, "a disciplina que permite diagnosticar as doenças inacessíveis à observação direta na base de sintomas superficiais, às vezes irrelevantes aos olhos leigos" (Ibid, p.151, grifo meu). Mais adiante no texto ele aponta a centralidade do par "clínico-olho" do conhecedor: (Ibid, p.159).
} 
evidência, mas o seu caráter criminoso.

Nesse sentido, o esfriamento emotivo nesse contexto investigativo não correspondia a uma "indiferença", frequentemente atribuída aos agentes das burocracias estatais (HERZFELD, 1992), e tampouco a uma "gramática de impotência", como sugere Durão (2013) no contexto da gestão policial da violência doméstica. Era, ao contrário, a resposta emotiva que justamente garantia as condições de possibilidade de ação policial diante de cenas de pornografia infantil e também o próprio efeito da neutralização da ameaça simbólica dessas imagens através do trabalho moral exercido pelo olhar do investigador. Afinal, a possibilidade de agir por meio da atividade investigativa minimiza o sofrimento diante dessas imagens assim como a impotência leva à tristeza, como foi destacado por um dos agentes. Enquanto a condição de sofredor é eminentemente passiva, a posição de denunciante e a de investigador é caracterizada por uma postura emocional ativa. Mas isso implica a substituição da "compaixão" em relação à vítima pelo sentimento de "indignação" orientado em direção ao culpado. E, em um segundo momento, existe uma exigência de deixar de lado os afetos, bem como a linguagem dramática e o estilo panfletário que caracteriza a postura do denunciante, para buscar as provas que permitam fundar a acusação na "realidade", como sugere Boltanski (1993, p.101-102).

Essas ideias tornaram-se particularmente evidentes no final da pesquisa de campo enquanto eu analisava um inquérito policial junto com um agente do núcleo, o que revela o valor heurístico de ter sido "afetada" pela experiência etnográfica. Comentei com o agente - e ele concordou - que, por mais que durante a análise dos inquéritos seja necessário abrir os CDs anexados aos laudos periciais e olhar as imagens na tela do computador, examiná-las nesse contexto é diferente do que analisá-las nas páginas de internet na primeira etapa de apuração da denúncia. No inquérito a imagem está capturada em um suporte no qual ela representa, antes de tudo, a materialidade de um crime. Já no site, a imagem está enquadrada em um contexto pornográfico no qual ela é voltada para a produção de excitação sexual no espectador - o que define justamente o seu caráter abjeto e monstruoso e gera uma enorme perturbação no público "não pedófilo".

Como vimos, a possibilidade de produzir excitação sexual parece ser uma das principais fantasmagorias em torno das imagens de pornografia infantil, o que mostra que estas são presumidamente dotadas de uma força agenciadora que pode ser descrita como um devir "pedófilo" ou pedofilização. Isso permite sugerir que esses arquivos digitais que circulam na internet 
e nos inquéritos policiais, de maneira semelhante às coisas trocadas nos sistemas da dádiva descritos por Mauss (2003), possuem alma ou potência. Isto é, assim como a dádiva, as imagens supostamente carregam o espírito do seu antigo proprietário que, neste caso, evidentemente não traz consigo uma virtude. Trata-se, antes, de uma transmissão de atributos malignos perigosamente contagiosos e de coisas envenenadas capazes de enfeitiçar e degenerar o observador. Nesse sentido, a "pedofilia" pode ser pensada simultaneamente a partir da noção de monstruosidade (FOUCAULT, 2002; LOWENKRON, 2012) - que combina o impossível, o proibido e o ininteligível - e em relação ao conceito de abjeção proposto por Butler (2002), o qual traz a ideia de exclusão e repúdio de uma zona de inabitabilidade que o sujeito supõe ameaçadora para sua própria integridade.

Proponho ainda que a "poluição" da infância produzida pela representação do corpo infantil segundo uma estética do erotismo adulto seja entendida no sentido proposto por Mary Douglas (1976), isto é, como algo que está "fora do lugar". Assim, o ato de deslocar essas cenas do perigoso e incontrolável território do erotismo (como as páginas pornográficas na internet e o computador do "pedófilo") para reinscrevê-las nas molduras do inquérito policial - que transforma as fotografias em materialidade do crime e suporte de incriminação - pode ser compreendido como uma estratégia de situá-las no "devido" lugar (o da proibição). Talvez este seja justamente um dos efeitos mais importantes do trabalho moral exercido por esses policiais, visto que o enquadramento criminal das imagens parece ser a única maneira de neutralizar o caráter poluidor desse gênero pornográfico. Ainda assim, como vimos, existe sempre a virtualidade e o risco de uma inesperada, perigosa e indesejável resposta erótica diante de essas cenas por parte daqueles que as visualizam durante a investigação criminal.

Se partirmos do pressuposto de que são os usos e os contextos de visualização e não os conteúdos em si que definem as propriedades das imagens (SONTAG, 2003), utilizá-las como "prova" do crime e suporte para uma denúncia é a única possibilidade de utilização "politicamente correta", moralmente segura e socialmente aceitável da pornografia infantil. Além disso, dado que é justamente no olhar do "pedófilo" que reside o elemento volitivo do tipo penal no caso da conduta do consumidor de pornografia infantil, o enquadramento criminal das imagens por meio do inquérito oferece ainda a "moldura interpretativa" (BUTLER, 2009) necessária para garantir a normalidade dos sujeitos que se dedicam a analisá-las no contexto investigativo através da diferenciação do olho analítico do 
policial em relação ao olhar transgressivo do "pedófilo"7. Não por acaso, ao se criminalizar a "posse" e o "armazenamento" de pornografia infantil (através da Lei 11.829 de 2008), inseriu-se no novo tipo penal uma previsão de exclusão de punibilidade para aqueles que guardam essas imagens não para "fins sexuais", mas sim com a finalidade de subsidiar uma investigação criminal (art. 241-B, § 2o, ECA, 1990).

É por isso também que, apesar do esfriamento necessário para realização do trabalho policial, é importante manifestar algum grau de repulsa ou, ao menos, de desinteresse diante das imagens, para que não recaia sobre os investigadores a acusação de "pedofilia". Isso revela que, diante da pornografia infantil, o controle ou a indiferença, associados por Lutz (1988) ao polo da racionalidade, não são suficientes para afastar o risco de ser contaminado pela eventual suspeita de interesse erótico. A força negativa da sua conotação moral é tão poderosa que, em certos momentos, para contrabalançar essa ameaça, é necessária a exibição de um sentimento de natureza oposta. Neste caso, a oposição não se dá mais entre o emocionar-se e ser racionalmente controlado ou entre emocionar-se e distanciar-se, como sugere a autora (ibid), mas entre dois tipos de afeto: o interesse erótico e a repulsa ${ }^{8}$.

Os próprios agentes do NUNET achavam que havia muito "pedófilo enrustido": "Há muitos colegas aí que ficam olhando as fotos e dizem 'ai, que horror', e ficam olhando com a maior atenção, a maior curiosidade... Você vê que ele tá gostando...". Portanto, a aparente espontaneidade da repulsa e do desinteresse caminha lado a lado com um valor moral de profunda obrigação dessa expressão o que, por sua vez, não exclui a sinceridade. Como nos lembra Mauss (1980, p.60), "tudo isso é, ao mesmo tempo, social e obrigatório e, no entanto, violento e natural: afetação e expressão [...] andam juntas". Até aqui analisei como as respostas emocionais socialmente inscritas e prescritas diante das imagens de pornografia infantil (que em outros contextos supõem a expressão de sentimentos como "repugnância", "horror" e "indignação"9 ) assumem um

\footnotetext{
${ }^{7}$ Para uma discussão mais aprofundada sobre isso, ver Lowenkron, 2013a.

${ }^{8}$ Agradeço a Maria Claudia Coelho por esta sugestão.

${ }^{9}$ Sobre a gestão das emoções em torno dessas imagens na arena pública e política da CPI da Pedofilia, ver Lowenkron, 2013b.
} 
caráter particularmente distanciado e frio no universo policial, encarnado pelo olhar clínico detetivesco. Argumentei que o aprendizado prático e sensorial dessa postura emocionalmente distanciada é apresentado como condição de possibilidade fundamental (ainda que possa ressurgir como ameaçadora e suspeita se levada ao limite extremo) para a realização do ofício investigativo policial. Com o intuito de mostrar como o saber prático e essa postura emotiva foram aos poucos incorporados também por mim ao longo do meu trabalho de campo no NUNET, considero interessante descrever, por fim, uma situação etnográfica na qual examino e seleciono junto com um policial os "indícios" de materialidade do crime.

Ao ser designado para analisar os arquivos de imagem gravados em um CD anexado ao laudo pericial, o agente do NUNET prefere imprimir algumas fotos que possam pautar a conclusão do delegado. Ele diz: "não sou especialista nisso de dizer a idade das pessoas a partir das suas características corporais. Uso o bom senso. Então, é melhor avaliarmos em conjunto". O policial lembra ainda a importância de sua "Informação"10, que vai influenciar toda a rede de tomadores de decisão, desde o delegado, passando pelo procurador da República até o juiz. Certo dia o agente me convida para acompanhar a sua análise de um inquérito (que ele diz ser interessante).

Ao analisar o laudo pericial, ele reclama que os peritos não informam nada direito, pois têm medo de se posicionar. Diz que soube pela escrivã que as procuradoras da República pedem para mandar os inquéritos para o NUNET analisar porque as informações saem "mastigadinhas". Ele me mostra que na parte do laudo que respondia ao quesito sobre se havia ou não sido encontrado material de pornografia infantil, os peritos diziam que as imagens haviam sido anexadas ao $\mathrm{CD}$, associadas a "palavras-chave". Entretanto, ao examinar o material, o agente observa que há várias imagens que podem ser evidentemente classificadas como pornografia infantil. Ele resolve, então, imprimir algumas para anexar à sua Informação, na qual afirma ter encontrado material ilícito.

O policial me pergunta se acho que tem que imprimir as imagens. Apesar

${ }^{10}$ Documento produzido pelo agente policial no qual ele informa seus procedimentos investigativos e suas impressões. Esta peça documental é anexada aos autos do inquérito e vai pautar as impressões e decisões de diferentes autoridades envolvidas no processo de acusação criminal. 
de saber que o novo delegado, depois de uma reunião com representantes do Ministério Público, está orientando a não colocar essas cenas nos autos para não atrair a atenção de "curiosos", o agente as considera uma peça de Informação importante já que não cabe a ele definir isoladamente se tem ou não pornografia infantil. "Se aquilo estiver ali, qualquer um que analisar os autos pode ver e chegar a sua própria conclusão", avalia. Sugiro-lhe fazer uma descrição detalhada das cenas, mas ele diz que a descrição não é a mesma coisa do que a imagem. Eu imediatamente concordo com o agente que as fotografias oferecem outro tipo de informação bem como são dotadas de especial força de agência emotiva e persuasiva ao trazerem em si o peso da materialidade dos corpos infantis envolvidos em cenas pornográficas.

Utilizando um software de análise de imagens que compara caracteres semelhantes, o agente verificou ainda que uma das fotos encontradas no exame pericial coincide com um dos arquivos disponibilizados no CD que deu origem à "busca e apreensão", no qual foram gravadas as fotografias que tinham sido divulgadas na internet - o que reforça o indício de que os policiais chegaram ao "alvo" correto. Ao analisar o inquérito, verifico que há também no laudo uma conversa de MSN (programa de comunicação instantânea) na qual foram realizadas trocas de arquivos.

Na conversa registrada, um usuário com o nome de Tereza pergunta a um de seus contatos com o nome de Jussara se gostava de PTHC, sigla que significa preteen hard core. De acordo com o policial, esses nomes provavelmente eram fictícios, pois utilizar um nick (codinome) feminino é uma estratégia comum utilizada por "pedófilos" na internet. Em seguida, Tereza convida Jussara a trocar arquivos e passa a enviar e receber imagens cujos títulos sugeriam tratar-se de conteúdo ilegal, mas que não podem ser visualizadas no registro das conversas. Ajudo-o a identificar os arquivos que foram trocados via MSN no CD anexado ao laudo pericial e conferimos que as imagens eram mesmo de "pornografia infantil". Sugiro ao agente colocar isso na sua peça de Informação porque configuraria materialidade do crime de "divulgação" de pornografia infantil (art. 241-A, ECA), além do delito de "posse" deste material (art. 241-B, ECA).

Propus ainda que ele trocasse a imagem que tinha escolhido para ilustrar a sua Informação, a qual retratava uma menina púbere, por alguma que tivesse uma criança mais nova. $\mathrm{O}$ agente seleciona uma foto de uma menina impúbere, que aparenta ter uns seis anos. Ela está nua, em posição fetal, com a bunda para cima. Primeiramente concordamos que era evidentemente menor. Mas depois observo que não se enquadra 
no tipo penal que define o que é "pornografia infantil" porque não tem a exibição de órgão genital. Escolho, então, a foto de uma menina de uns cinco anos mantendo intercurso sexual vaginal com um adulto. O policial seleciona mais uma cena pornográfica de dois meninos de uns nove ou dez anos fazendo sexo oral um no outro. Por fim, imprimimos as imagens selecionadas em tamanho relativamente pequeno para não parecer nada muito "apelativo" e anexamos à Informação a materialidade dos corpos e do crime.

\section{Considerações finais}

Ao reler as notas de campo sobre essa situação etnográfica algum tempo depois, notei que, sem perceber, eu havia sido "afetada" no sentido proposto por Favret-Saada (1990), isto é, havia estabelecido com o agente policial uma modalidade de comunicação inconsciente e involuntária de afetos e percepções em torno das imagens de pornografia infantil. Ao narrar essa cena na qual seleciono estrategicamente junto com um dos agentes do NUNET as imagens que apresentam os mais indubitáveis indícios de materialidade de que o crime investigado havia sido cometido pelo "alvo" do inquérito analisado, pretendi mostrar como incorporei o saber prático policial, que pode ser definido por uma postura de esfriamento emotivo e um olhar analítico necessários para realização do ofício investigativo tanto o policial quanto o antropológico. Afinal, se eu quisesse realizar uma "observação-participante" dessas investigações e compreender o trabalho daqueles policiais, era preciso pouco a pouco substituir o "mal-estar", o "horror" e a "repulsa" diante das cenas de pornografia infantil por uma forma de olhar direcionada para a eficácia da acusação criminal.

Isso envolveu aprender a reconhecer e saber manipular o potencial emotivo e persuasivo das imagens, o que me levou a compreender que o esfriamento não significa necessariamente um desengajamento moral que tanto assombrava os policiais pela ameaça de serem confundidos com o monstro que se esforçavam para combater. Trata-se, antes, da característica distintiva do "olho clínico" policial, capaz de realizar uma análise "objetiva" dos "fatos" necessária para garantir a condenação legal e moral do acusado. Para isso, era preciso fazer a emoção calar e orientar a atenção para o mundo das provas (BOLTANSKI, 1993).

Ao longo da pesquisa de campo, aprendi com os policiais a adotar esse 
novo modo de sentir e examinar as imagens de pornografia infantil, o que implicou um deslocamento dos sentimentos subjetivos aos fatos objetivos. Esse aprendizado, que só foi possível a partir da experiência de ter sido afetada pela força da exposição contínua a essas imagens dentro da moldura interpretativa fornecida pelo contexto das investigações criminais e dos inquéritos policiais, foi fundamental para o meu ofício etnográfico, assim como o era para o exercício da atividade de investigação criminal. A partir disso, foi possível não apenas observar e compreender melhor o trabalho dos investigadores do NUNET, mas também participar cada vez mais da atividade de análise das imagens de pornografia infantil junto com eles e transformar essa participação em instrumento de conhecimento.

\section{Referências}

BOLTANSKI, Luc.

(1993). La Suffrance a Distance: Morale Humanitaire, Médias et Politique. Paris, Éditions Métailie.

BRASIL.

(1990). Lei no 8.069 - Estatuto da Criança e do Adolescente (ECA).

BUTLER, Judith.

(2009). Frames of war: when is life grievable? London and New York, Verso.

(2002). Cuerpos que Importam: sobre los limites materiales y discursivos del "Sexo". Buenos Aires, Paidós.

COELHO, Maria Claudia.

(2010). Narrativas da violência: a dimensão micropolítica das emoções. Mana, vol.16, n.2, p. 265-285.

DÍAZ-BENÍTEZ, María Elvira.

(2010). Nas Redes do Sexo: Os Bastidores do Pornô Brasileiro. Rio de Janeiro, Zahar.

DOUGLAS, Mary.

(1976). Pureza e Perigo. São Paulo, Perspectiva.

DURÃO, Susana.

(2013). Violências privadas como se fossem direitos públicos: perspectivas antropológicas. Mana, vol. 19, n. 2, p. 277302.

FAVRET-SAADA, Jeanne.

(1990). Être Affecté. Gradhiva: Revue d'Histoire et d'Archives de l'Anthropologie, 8, p. 3-9.

FERREIRA, Letícia Carvalho de Mesquita.

(2009). Dos Autos da Cova Rasa: a identificação de corpos não-identificados no Instituto Médico-Legal do Rio de Janeiro, 1942-1960. Rio de Janeiro, E-papers / LACED.

FOUCAULT, Michel.

(2009). Seguridad, territorio y población: curso em el Collège de France - 1977-1978. Buenos Aires, Fondo de Cultura Económica.

(2002). Os Anormais. São Paulo, Martins Fontes.

(1997). Vigiar e Punir: nascimento da prisão. Tradução de RAMALHETE, R. 15a. ed. Petrópolis, Vozes.

(1988). História da sexualidade I: A vontade de saber. Rio de Janeiro, Edições Graal.

GINZBURG, Carlo.

(1989). Sinais: Raízes de um Paradigma Indiciário. In: Carlo Ginzburg (Ed.); Mitos, Emblemas, Sinais: morfologia e história. São Paulo, Companhia das Letras. p.143-179. 
HERZFELD, Michael.

(1992). The Social Production of Indifference. Exploring the Symbolic Roots of Western Bureaucracy. New York / Oxford, Berg Publishers.

LEITE Jr, Jorge.

(2006). Das Maravilhas e Prodígios Sexuais: a pornografia "bizarra" como entretenimento. São Paulo, Annablume.

LOWENKRON, Laura.

(2013a). A cruzada antipedofilia e a criminalização das fantasias sexuais. Sexualidad, Salud y Sociedad - Revista Latinoamericana, n.15, p.37-61.

(2013b). "All against pedophilia": ethnographic notes about a contemporary moral crusade. Vibrant, v. 10, n. 2, p. 41-72 .

(2012). O Monstro Contemporâneo: a construção social da pedofilia em múltiplos planos. Tese de doutorado apresentada ao Programa de Pósgraduação em Antropologia Social (PPGAS) no Museu Nacional (MN) da Universidade Federal do Rio de Janeiro (UFRJ).

LUTZ, Catherine.

(1988). Unnatural emotions: everyday sentiments on a Micronesian atoll and their challenge to Western theory. Chicago, University of Chicago Press.

LUTZ, Catherine e ABU-LUGHOD, Lila (Orgs.). (1990). Language and the politics of emotion. Cambridge, Cambridge University Press.
MAUSS, Marcel.

(2003). Ensaio sobre a Dádiva: forma e razão da troca nas Sociedades Arcaicas. In Marcel Mauss (Ed.); Sociologia e Antropologia. São Paulo, Cosac \& Naify, p.185-314.

(1980). A Expressão Obrigatória dos Sentimentos. In : Servulo Figueira (Ed.), Psicanálise e Ciências Sociais. Rio de Janeiro, Francisco Alves.

MILLER, William Ian.

(1997). Tha Anatomy of Disgust. Cambridge / Massachusetts / London, Harvard University Press.

RABEL0, Mariana Cintra.

(2012). Salvar cordeiros imolados: a gestão do combate à pornografia infantil na internet e a proteção de crianças. Dissertação de Mestrado apresentada a Universidade de Brasília.

RICHARDSON, Ruth.

(2000). Death, Dissection and the Destitute. Chicago, The University of Chicago Press.

SONTAG, Susan.

(2003). Diante da Dor dos Outros. São Paulo, Companhia das Letras.

\section{Recebido em}

dezembro de 2016

\section{Aprovado em}

março de 2017 